\title{
Risk and Protective Factors Associated With Intimate Partner Violence in a Nationally Representative Sample of Korean Men
}

\section{Riccardo Ferraresso}

Department of Police Sciences, Dongguk University, Seoul, Korea

Objectives: In recent years, multiple studies have investigated the issue of intimate partner violence (IPV) in Korea. However, most of those studies have focused on IPV against women, while overlooking the problem of men IPV victimization. Considering this, the current study identified risk and protective factors for IPV and examined their influence on IPV victimization among Korean men.

Methods: We used a nationally representative sample of 1668 Korean men from the 2013 Korea National Survey on Domestic Violence. The associations between potential IPV risk factors and different types of IPV were investigated using univariate and multivariate logistic regression. Specifically, separate analyses were conducted of 5 types of IPV (neglect, controlling behaviors, emotional violence, economic violence, and physical violence).

Results: The prevalence of IPV among Korean men and women showed only marginal gender differences. Controlling behaviors (men, 23.3\%; women, 23.9\%) and emotional violence (men, 16.5\%; women, 18.8\%) were the most common types of IPV reported, followed by neglect (men, 11.2\%; women, 11.7\%). Separate logistic regression analyses for the 5 subtypes of IPV revealed that mutual IPV was a strong predictor of IPV. Men who abused their wives were more likely to experience neglect (odds ratio [OR], 29.24; $p<0.01$ ), controlling behaviors (OR, 36.61; $p<0.01)$, emotional violence $(\mathrm{OR}, 58.07 ; p<0.01)$, economic violence $(\mathrm{OR}, 18.78 ; p<0.01)$, and physical violence (OR, 38.09; $p<0.01)$.

Conclusions: The findings of this study suggest that IPV intervention strategies should particularly focus on couples whose relationship is characterized by patterns of bidirectional violence.

Key words: Intimate partner violence, Men, Victimization, Risk factors, Protective factors, Korea

\section{INTRODUCTION}

Intimate partner violence (IPV) refers to a wide range of behaviors that can inflict physical, psychological, and sexual harm

Received: October 29, 2019 Accepted: February 3, 2020

Corresponding author: Riccardo Ferraresso, PhD Department of Police Sciences, Dongguk University, 30 Pildong-ro

1-gil, Jung-gu, Seoul 04210, Korea

E-mail: rferraresso@dongguk.edu

This is an Open Access article distributed under the terms of the Creative Commons Attribution Non-Commercial License (https://creativecommons.org/licenses/by$\mathrm{nc} / 4.0 / /)$ which permits unrestricted non-commercial use, distribution, and reproduction in any medium, provided the original work is properly cited. on a person who is or was in an intimate relationship with the offender [1]. IPV can be exercised by inflicting or threatening to inflict physical injuries, forced gender, or psychological abuse. IPV often occurs concurrently with economically abusive behaviors, which can reduce the victim's ability to achieve economic independence, or controlling behaviors, which include monitoring a partner's movements and isolating him or her from family and friends.

Data published by the World Health Organization (WHO) show that while IPV is a global health issue, the estimated prevalence of IPV varies greatly among regions, ranging from $21 \%$ in North America to $43 \%$ in South Asia, as well as among coun- 
tries within those regions [2]. In Korea, triennial national surveys administered since 1997 by the Ministry of Family and Gender Equality have provided a wealth of information about IPV in Korean society. The first National Survey on Domestic Violence found that more than one-quarter of women respondents (27.9\%) had experienced physical abuse, exceeding the prevalence rates reported in several developing countries such as Egypt (13\% in 1995/1996) and India (10\% in 1998/2000) [3]. Subsequent national surveys recorded a stable decline in the reported rate of women's experience of physical IPV, which dropped to $9.4 \%$ in 2007 and 3.3\% in 2016. Men's experience of IPV similarly followed a declining trend (15.8\% in 1997, 6.4\% in 2007, and $1.6 \%$ in 2016).

Researchers investigating the high rates of domestic violence in a country otherwise characterized by low crime rates have emphasized Korean social structure and the role of women in Korean society as major factors that explain this inconsistency. Indeed, the implications of strong adherence to Confucian values, which embrace patriarchal ideas about the submissive role of Korean women to their fathers before marriage and to husbands after marriage, have been the focus of discussions on the high prevalence of IPV victimization among Korean women $[4,5]$. The emphasis on patriarchy and masculinity in Korean culture has served as a critical starting point for a society-wide reflection on the need to address cultural and social attitudes toward IPV against women. Nonetheless, Korean men are also at a high risk of becoming victims of domestic abuse, and society should not ignore their pain and suffering. In fact, the latest findings from the 2016 National Survey show that while the prevalence of woman IPV victimization involving physical, sexual, psychological, and/or economic abuse was $12.1 \%$; a staggering $8.6 \%$ of Korean men reported having experienced at least 1 of those types of violence as well. Moreover, the proportion of IPV victimization when including controlling behaviors was $33.4 \%$ and $33.1 \%$ for women and men, respectively.

Until recently, the debate on IPV has been dominated by the tendency to see IPV as a type of violence affecting women. Nevertheless, a growing body of research over the last 4 decades has drawn more attention to the phenomenon of women perpetration of violence towards their partners, the relative gender symmetry in IPV, the impact on the physical health and psychological health of men victims of IPV, and the difficulties faced by men victims when dealing with the criminal justice system or trying to access services offered to victims of
IPV $[6,7]$. The growing evidence of man IPV victimization highlights the importance of investigating the risk and protective factors associated with partner violence perpetrated towards men. Researchers have identified several factors associated with men IPV victimization. Older age has been generally found to be a protective factor against IPV for both men and women $[8,9]$. For instance, South African young adults were 3 times more likely to report IPV victimization than those aged 65 years or older. Similarly, Lee et al. [10] found that Korean men were less likely to inflict or become the target of verbal and physical abuse as they aged. The relationship between education and $\mathrm{IPV}$ victimization is also clear, as research indicates that individuals with no or low educational attainment tend to be at higher risk [11]. In a study of a large sample of Korean men, individuals who had graduated from middle or high school or attained a college degree were significantly less likely to report IPV victimization than those with only an elementary school education or less [10]. In terms of employment status, individuals who are unemployed or low-income earners are typically more likely to experience IPV victimization [12-14]. However, employment status may not necessarily have the same impact on men and women. Lee et al. [10] found that while jobless men were at a slightly lower risk of IPV victimization than those who were employed full-time or part-time, the same association was not present for women. In another study involving 1148 Hispanic men and 1399 Hispanic women, Cunradi [9] found that men employed full-time were at significantly higher risk of IPV victimization than a control group including students, disabled individuals, retired people, and homemakers. In addition, several studies have taken into consideration the developmental experiences of victims, including being a victim of child abuse and witnessing IPV between parents during childhood. These studies have pointed to a significant relationship between such experiences and higher risks of becoming victims of IPV for both men and women $[12,15,16]$. Finally, previous studies have reported that IPV occurred at a higher frequency in partnerships where violence was not unidirectional $[17,18]$. For instance, a recent study surveyed a group of married men and women living in Tehran, Iran, and found that physical violence against the female spouse was a strong (and the only significant) predictor of physical victimization of men in IPV [19].

Domestic abuse against male partners is a serious, yet understudied issue. Partner violence was initially conceptualized as a gendered issue, and the role of men as victims of IPV has 
often been sidelined [20]. Although some studies have explored this issue, research on IPV has often relied on small samples and primarily focused on certain types of IPV (physical/sexual violence and/or psychological violence). Furthermore, research on men IPV victimization has been primarily conducted in Western nations, which tend to show higher levels of gender equality and women's empowerment than Korea. This article used the 2010 National Survey of Domestic Violence to examine the risk factors associated with IPV victimization of Korean men. This analysis included the 5 types of IPV measured by the survey: neglect, controlling behaviors, economic violence, emotional violence, and physical violence.

\section{METHODS}

This study analyzed data from the 2010 National Survey of Domestic Violence. The Welfare Support Division within the Ministry of Gender Equality and Family oversaw the survey, for which 3800 representative households distributed across 200 districts were visited from August 2010 through October 2010 [3]. The final sample included a total of 5000 respondents aged 18 or older. Of the respondents, $3332(66.6 \%)$ were women respondents and 1668 (33.4\%) were men respondents [21]. For the purpose of this secondary data analysis, we selected a subgroup that included all 1668 of the men respondents.

\section{Dependent Variables}

Binary variables measuring the 5 subcategories of IPV victimization were used as the outcome variables. The 5 types of IPV victimization included neglect, controlling behaviors, emotional violence, economic violence, and physical violence. A subset of questions from the Straus Revised Conflict Tactics Scale and the WHO was used to assess respondents' experience of different forms of IPV.

\section{Independent Variables}

\section{Socio-demographic factors}

All subjects had reached the age of majority at the time of the survey and their age was measured as a continuous variable. Employment status was dichotomized as 0 (unemployed) and 1 (employed). Monthly family income and education were measured as ordinal variables. In the survey, monthly family income (US\$) was coded as 1 (no income), 2 (less than 1000), 3 (1000-2000), 4 (2000-3000), 5 (3000-4000), 6 (4000-5000), and 7 (more than 5000), while education was coded as 1 (ele- mentary school or no formal education), 2 (middle school), 3 (high school), and 4 (college or higher). Both variables were treated as continuous variables for the purpose of this analysis. Finally, a dichotomous variable labeled 'urbanity' was coded as 0 if the subject reported living in a metropolitan city or 1 if the subject lived in a non-urban area.

\section{History of domestic violence}

The severity of child abuse victimization was constructed as the sum of 6 items. Respondents were asked if they had experienced any of the following forms of abuse during childhood: (1) being verbally abused; (2) having the hands or calf hit with a cane; (3) getting punched, slapped, or kicked; (4) getting hit with an object; (5) being deprived of food or medical treatment; and (6) being left alone in situations requiring parental supervision. The Cronbach alpha coefficient for the 6 items was 0.701 . In addition, a variable measuring the extent to which respondents had witnessed inter-partner violence between their parents during childhood was defined by adding 3 items that asked respondents whether their parents had ever engaged in behavior such as hitting each other, throwing objects at each other, or verbally abusing each other. The Cronbach alpha coefficient for these 3 items was 0.675 .

\section{Acceptance of violence}

Approval of the use of violence was measured by adding 5 items scored on a 4-point Likert scale. Each item measured the degree to which respondents accepted the use of violence as a viable way to settle personal and social conflicts. The Cronbach alpha coefficient for these 5 items was 0.826 .

\section{Mutual violence}

Approval of the use of violence was measured by adding 5 items scored on a 4-point Likert scale. Each item measured the degree to which respondents accepted the use of violence as a viable way to settle personal and social conflicts. The Cronbach alpha coefficient for these 5 items was 0.826 .

\section{Statistical Analysis}

The associations of each category of IPV with the independent variables were assessed through univariate and multivariate logistic regression models. Univariate logistic regression models were first used to evaluate the relationships between each factor and the independent variables. The factors that were found to be significant at the 0.05 level of significance in 
the univariate analysis were included as independent variables in the multivariate model. This procedure was used to separately analyze the 5 categories of IPV. All analyses were conducted using SPSS version 22 (IBM Corp., Armonk, NY, USA).

\section{Ethics Statement}

The ethical approval or individual consent was not applica-

Table 1. Characteristics of the participants $(n=1668)$

\begin{tabular}{lc}
\hline Variables & n (\%) or mean \pm SD (Min-Max) \\
\hline Experienced IPV victimization & $196(11.8)$ \\
Neglect & $412(24.7)$ \\
Controlling behaviors & $289(17.3)$ \\
Emotional violence & $22(1.3)$ \\
Economic violence & $196(12.0)$ \\
Physical violence & \\
Perpetration of IPV & $246(14.7)$ \\
Neglect & $450(27.0)$ \\
Controlling behaviors & $353(21.2)$ \\
Emotional violence & $46(2.8)$ \\
Economic violence & $68(4.1)$ \\
Physical violence & \\
Employment status & $1308(78.4)$ \\
Employed & \\
Urbanity & $902(54.1)$ \\
Urban & $45.15 \pm 15.34(19-89)$ \\
Age (y) & $4.66 \pm 1.53(1-7)$ \\
Family income & $3.27 \pm 0.89(1-4)$ \\
Education & $1.56 \pm 1.46(0-6)$ \\
Child abuse & $0.71 \pm 0.93(0-3)$ \\
Witnessed violence between parents & $9.04 \pm 2.80(5-19)$ \\
Acceptance of violence & \\
\hline SD standad devation; & \\
\hline
\end{tabular}

SD, standard deviation; Min, minimum; Max, maximum; IPV, intimate partner violence. ble. Data obtained from the Ministry of Gender Equality and Family were used in this study.

\section{RESULTS}

Table 1 shows the mean, range, and standard deviation of all the variables of interest in the current study. Of particular note, emotional violence (17.3\%) and controlling behaviors (24.7\%) were the 2 most common forms of IPV experienced by Korean men, but a higher percentage of Korean men also reported inflicting those 2 types of abuse on their women partners ( $21.2 \%$ and $27.0 \%$, respectively).

\section{Intimate Partner Violence \\ Model 1: neglect}

Table 2 (model 1) presents the results of the multivariate logistic regression analysis for factors associated with experiencing neglect. All variables except education and urbanity were included in the multivariate regression model. However, only witnessing IPV between one's own parents during childhood (odds ratio [OR], 1.40; $p<0.05$ ) and neglecting one's own partner $(\mathrm{OR}, 29.24 ; p<0.01)$ were statistically significant in the final model, and both were associated with an increased likelihood of men victimization through neglect. Based on the HosmerLemeshow goodness-of-fit test, the data fit the model adequately $(p=0.05)$.

\section{Model 2: controlling behaviors}

The use of controlling behaviors in the intimate relationship was the second category of IPV that was assessed (model 2 in Table 2). Five factors remained significant in the multivariate logistic regression model. Of the socio-demographic factors

Table 2. Multivariate logistic regression analyses of factors associated with intimate partner violence

\begin{tabular}{lccccc}
\hline Variables & Model 1 & Model 2 & Model 3 & Model 4 & Model 5 \\
\hline Age & $1.01(0.99,1.02)$ & $1.01(1.00,1.02)^{*}$ & $1.02(1.00,1.03)^{\dagger}$ & - & - \\
Employment & $1.44(0.79,2.61)$ & $1.72(1.07,2.73)^{*}$ & $2.30(1.29,4.08)^{*}$ & - & - \\
Family income & $1.12(0.97,1.28)$ & $1.20(1.06,1.35)^{*}$ & - & $1.29(0.95,1.73)^{\dagger}$ & $1.50(1.11,2.00)^{*}$ \\
Education level & - & - & $1.03(0.78,1.35)$ & - & - \\
Urbanity & - & - & - & - & $0.32(0.13,0.77)^{*}$ \\
Child abuse & $0.93(0.78,1.09)$ & $1.06(0.92,1.21)$ & $1.18^{*}(1.01,1.38)$ & $1.25(0.95,1.64)$ & $0.84(1.59,1.20)$ \\
Witnessed violence between parents & $1.40(1.09,1.80)^{*}$ & $1.26(1.01,1.55)^{*}$ & $1.11(0.87,1.40)$ & - & $1.59(0.97,2.61)^{\dagger}$ \\
Acceptance of violence & $1.04(0.96,1.11)$ & $0.95(0.95,1.06)$ & $0.99(0.92,1.06)$ & $1.15(0.98,1.35)^{\dagger}$ & $1.01(0.96,1.06)$ \\
Mutual violence & $29.24(19.64,43.51)^{* *}$ & $36.61(26.60,50.37)^{* *}$ & $58.07(39.06,86.32)^{* *}$ & $18.78(7.04,50.03)^{* *} 38.09(16.06,90.29)^{* *}$ \\
\hline
\end{tabular}

Values are presented as odds ratio (95\% confidence interval).

${ }^{\dagger} p<0.1,{ }^{*} p<0.05,{ }^{* *} p<0.01$. 
that were analyzed, being older $(\mathrm{OR}, 1.01 ; p<0.05)$, being employed $(\mathrm{OR}, 1.72 ; p<0.05)$ and having a higher level of education $(\mathrm{OR}, 1.20 ; p<0.05)$ were associated with higher levels of victimization. As with victimization through neglect, those who witnessed violence between their parents during childhood $(\mathrm{OR}, 1.26 ; p<0.05)$ and used controlling behaviors against their woman partner $(\mathrm{OR}, 36.61 ; p<0.01)$ were more likely to be victimized. Based on the outcome of the Hosmer-Lemeshow goodness-of-fit test, the multiple logistic regression model fit the data well $(p=0.142)$.

\section{Model 3: emotional violence}

Three factors-being employed (OR, 2.30; $p<0.05)$, having experienced child abuse during childhood (OR, 1.18; $p<0.05)$, and engaging in emotional violence against the female partner (OR, 58.07; $p<0.01)$ —were found to be statistically significant in the multivariate logistic regression model assessing factors associated with victimization through emotional violence (model 3 in Table 2). In addition, older age was also found to be positively associated with victimization through emotional violence, but the variable was only significant at the 0.1 level. The Hosmer-Lemeshow goodness-of-fit test indicated that the model fit the data well $(p=0.109)$.

\section{Model 4: economic violence}

Among the independent variables included in the multivariate logistic regression model of factors associated with economic violence, perpetrating economic violence against the woman partner $(\mathrm{OR}, 18.78 ; p<0.01)$ was statistically associated with male victimization through economic violence (model 4 in Table 2). Two other factors-higher family income (OR, 1.29; $p<0.1)$ and positive attitudes towards violence (OR, 1.15; $p<0.1$ - were associated with a higher likelihood of victimization against men, but the variables were only significant at the 0.1 level. The data fit the model well $(p=0.796)$.

\section{Model 5: physical violence}

The last model examined the relationship between the independent variables and victimization through physical violence (model 5 in Table 2). Inflicting physical violence on one's intimate partner (OR, 38.09; $p<0.01)$, having a higher family income (OR, 1.50; $p<0.05)$, and living in an urban areas (OR, $0.32 ; p<0.05)$ were associated with higher levels of victimization through physical violence. Furthermore, Korean men who perpetrated physical abuse against their partner were more likely to be victimized. Positive attitudes towards the use of violence was found to be the only significant risk factor in this model (OR, $1.59 ; p<0.1)$, but only at the 0.1 level. According to the Hosmer-Lemeshow test, the data fit the model well ( $p=$ 0.886).

\section{DISCUSSION}

This study examined the risk factors associated with IPV victimization among Korean men for 5 forms of IPV by analyzing data from the 2010 Korean National Study on Domestic Violence. According to a preliminary analysis of the dataset, we found that the prevalence of men IPV victimization ranged from $1.7 \%$ to $23.3 \%$, depending on the type of abuse. Furthermore, a comparison of the prevalence of IPV between men and women respondents showed strikingly similar rates of exposure to partner violence over the last 12 months for some forms of partner violence, such as being neglected by the partner (men, 11.7\%; women, $12.1 \%$ ), controlling behaviors (men, $24.7 \%$; women, $25.6 \%$ ), and emotional violence (men, $17.3 \%$; women, 19.5\%). However, for economic violence (men, 1.3\%; women, $2.4 \%$ ) and physical violence (men, $1.8 \%$; women, $3.3 \%$ ), the overall prevalence was lower, but these forms of abuse were disproportionately experienced by women. These data corroborate some of the early claims on gender symmetry in patterns of marital violence presented in the works of Straus [22] and Steinmetz [23], and provide further support for the research on bidirectional IPV conducted in Western countries [8,24-29].

Moving to the results of the regression analyses, our findings partially reflected those of previous research on male IPV victimization, with some distinctions across the broad spectrum of IPV types included in the study. The traumatizing experience of having been abused by violent parents or witnessing violent interactions between one's parents during childhood was significantly associated with experiencing neglect (OR, 1.40; $p<0.05)$, controlling behaviors (OR, 1.26; $p<0.05)$, emotional violence $(\mathrm{OR}, 1.18 ; p<0.05)$, and physical violence $(\mathrm{OR}, 1.59$; $p<0.1$ ). The positive association between a history of violence within the family during childhood and partner violence in adulthood is consistent with findings from previous research $[30,31]$. This result suggests that preventive strategies targeting at-risk individuals with a history of violence could contribute to disrupting the cycle of violence across generations. For instance, an empirical analysis of school-based and communitybased violence prevention programs for at-risk youths showed 
encouraging results [32].

Nonetheless, some of the other results appear to be at odds with the majority of studies in the broader literature. First, while younger age has traditionally been found to be associated with a higher risk of IPV victimization [33,34], a recent study identified becoming older as a risk factor for higher IPV victimization among a large sample of Asian-Pacific women [15]. On a similar note, unexpected positive associations were found between being employed and higher family income and a higher likelihood of woman-to-man partner violence. The former factor (being employed) was associated with a higher risk of IPV victimization in the form of controlling behaviors (OR, $1.72 ; p<0.05)$ and emotional violence (OR, 2.30; $p<0.05)$. The latter factor (higher family income) was also positively associated with some of the IPV measures, including controlling behaviors ( $\mathrm{OR}, 1.20 ; p<0.05)$, economic violence $(\mathrm{OR}, 1.29 ; p<0.1)$, and physical violence $(\mathrm{OR}, 1.50 ; p<0.05)$. Such findings are in contrast with most of the previous literature on IPV victimization. In particular, Ahmadabadi et al. [35] argued that once family income is disaggregated into the husband's income, the wife's income, and gender imbalance in income, men in the lower income group were more likely to report IPV victimization (except physical violence).

Of all the significant predictors in each logistic regression model, inflicting the same form of abuse on the partner was the strongest predictor of men IPV victimization. This association was stronger for emotional violence $(\mathrm{OR}, 58.07 ; p<0.01)$ and physical violence $(\mathrm{OR}, 38.09 ; p<0.01)$ than it was for the other forms of IPV. Our results are consistent with previous studies on women IPV victimization showing that patterns of bidirectional IPV tend to be characterized by a higher frequency of reported victimization than is found among women who are only victims or perpetrators of domestic abuse [36].

Indeed, the large effect size of mutual violence suggests that clinicians should ascertain the presence and nature of a pattern of bidirectional violence, and use approaches that are more effective at breaking the cycle of violence between partners. Such interventions can achieve the desired outcomes if they can effectively instill beliefs in non-violent conflict resolution and effective communication skills, while helping the couple learn control strategies that can contribute to a better management of power dynamics and imbalances between partners $[37,38]$. A recent evaluation of an intervention program aimed at violence within couples demonstrated success of a dyadic intervention model based on a psycho-educational, cognitive-behavioral approach delivered separately to men and women [39]. The authors found that both male and female participants reported engaging in fewer acts of physical violence and experiencing less physical abuse. A 1-year followup also revealed that men were less likely to have participated in general violence [39]. As high-quality research continues to explore IPV also in the context of Korea, it is important that researchers and practitioners consider the promising results of studies on dyadic intervention approaches to design programs that can target mutually violent couples, especially those in which the partners do not wish to separate.

Finally, this study has some limitations that should be addressed. First, the cross-sectional nature of this research allowed us to identify significant relationships between risk factors and IPV victimization, but not to infer causal relationships. Second, the prevalence of man IPV victimization (as well as IPV perpetration) only measured whether such events occurred in the previous 12 months. Hence, this study may not account for all IPV victimization experienced by the individuals included in the sample. Third, although we included a measure of mutual violence, we could not assess the frequency of such violence, its directionality (i.e., who started the violent behavior), and whether the partner's violence was escalation, revenge, selfdefense, or had other motivations. Therefore, future research should try to contextualize the circumstances of partners' interactions in the context of mutual IPV.

\section{CONFLICT OF INTEREST}

The author has no conflicts of interest associated with the material presented in this paper.

\section{FUNDING}

None.

\section{ACKNOWLEDGEMENTS}

None.

\section{AUTHOR CONTRIBUTIONS}

All work was done by RF. 


\section{ORCID}

Riccardo Ferraresso https://orcid.org/0000-0002-5167-4107

\section{REFERENCES}

1. Krug EG, Mercy JA, Dahlberg LL, Zwi AB. The world report on violence and health. Lancet 2002;360(9339):1083-1088.

2. Solotaroff JL, Pande RP. Violence against women and girls: lessons from South Asia; 2014 [cited 2020 Feb 13]. Available from: https://www.girlsnotbrides.org/resource-centre/violence-against-women-and-girls-lessons-from-south-asia/.

3. Kim JY, Oh S, Nam Sl. Prevalence and trends in domestic violence in South Korea: findings from national surveys. J Interpers Violence 2016;31(8):1554-1576.

4. Danis FS, Lockhart LL. Domestic violence: intersectionality and culturally competent practice. New York: Columbia University Press; 2010, p. 165-168.

5. Barrett K, George W. Race, culture, psychology, \& law. Thousand Oaks: Sage Publications; 2005, p. 257-268.

6. Randle AA, Graham CA. A review of the evidence on the effects of intimate partner violence on men. Psychol Men Masc 2011;12(2):97-111.

7. Hines DA, Douglas EM. Women's use of intimate partner violence against men: prevalence, implications, and consequences. J Aggress Maltreat Trauma 2009;18(6):572-586.

8. Caetano R, Vaeth PA, Ramisetty-Mikler S. Intimate partner violence victim and perpetrator characteristics among couples in the United States. J Fam Violence 2008;23(6):507-518.

9. Cunradi CB. Intimate partner violence among Hispanic men and women: the role of drinking, neighborhood disorder, and acculturation-related factors. Violence Vict 2009;24(1):83-97.

10. Lee M, Stefani KM, Park EC. Gender-specific differences in risk for intimate partner violence in South Korea. BMC Public Health 2014;14:415

11. Sorenson SB, Upchurch DM, Shen H. Violence and injury in marital arguments: risk patterns and gender differences. Am J Public Health 1996;86(1):35-40.

12. Mercado J, Bautista L, Urrutia JD, Morelos MJ, Amora JG. Analysis on predicting spousal physical violence in the Philippines using binary logistic regression. Eur Acad Res 2015;3(3):31453166.

13. Tollestrup K, Sklar D, Frost FJ, Olson L, Weybright J, Sandvig J, et al. Health indicators and intimate partner violence among women who are members of a managed care organization.
Prev Med 1999;29(5):431-440.

14. Browne A, Salomon A, Bassuk SS. The impact of recent partner violence on poor women's capacity to maintain work. Violence Against Women 1999;5(4):393-426.

15. Jewkes R, Fulu E, Tabassam Naved R, Chirwa E, Dunkle K, Haardörfer R, et al. Women's and men's reports of past-year prevalence of intimate partner violence and rape and women's risk factors for intimate partner violence: a multicountry cross-sectional study in Asia and the Pacific. PLoS Med 2017; 14(9):e1002381.

16. van Wijk NP. Domestic violence by and against men and women in Curaçao: a Caribbean study [dissertation]. Amsterdam: Vrije Universiteit; 2012 (German).

17. Whitaker DJ, Haileyesus T, Swahn M, Saltzman LS. Differences in frequency of violence and reported injury between relationships with reciprocal and nonreciprocal intimate partner violence. Am J Public Health 2007;97(5):941-947.

18. Sagrestano LM, Heavey CL, Christensen A. Perceived power and physical violence in marital conflict. J Soc Issues 1999; 55(1):65-79.

19. Nikparvar F, Stith S, Anderson J, Panaghi L. Intimate partner violence in Iran: factors associated with physical aggression victimization and perpetration. J Interpers Violence 2018: 886260518759060.

20. Donovan C, Hester M. 'I hate the word "victim"': an exploration of recognition of domestic violence in same sex relationships. Soc Policy Soc 2010;9(2):279-289.

21. Korean Women's Development Institute. The domestic violence survey in 2013 [cited 2020 Mar 22]. Available from: http://www. ndsl.kr/ndsl/search/detail/report/reportSearchResultDetail. do?cn = TRKO201600013306 (Korean).

22. Straus MA. Wife beating: how common and why? Victimology 1977;2(3-4):443-458.

23. Steinmetz SK. The battered husband syndrome. Victimology 1977;2(3-4):499-509.

24. Stets JE, Hammons SA. Gender, control, and marital commitment. J Fam Issues 2002;23(1):3-25.

25. Straus MA, Gelles RJ, Steinmetz SK. Behind closed doors: violence in the American family. New York: Transaction Publishers; 2006, p. 36-38.

26. Moffitt TE, Caspi A. Findings about partner violence from the dunedin multidisciplinary health and development study; 1999 [cited 2019 Aug 28]. Available from: https://www.ncjrs. gov/pdffiles1/170018.pdf.

27. Houry D, Rhodes KV, Kemball RS, Click L, Cerulli C, McNutt LA 
et al. Differences in female and male victims and perpetrators of partner violence with respect to WEB scores. J Interpers Violence 2008;23(8):1041-1055.

28. Capaldi DM, Owen LD. Physical aggression in a community sample of at-risk young couples: gender comparisons for high frequency, injury, and fear. J Fam Psychol 2001;15(3):425-440.

29. Archer J. Sex differences in aggression between heterosexual partners: a meta-analytic review. Psychol Bull 2000;126(5): 651-680.

30. Widom CS, Czaja S, Dutton MA. Child abuse and neglect and intimate partner violence victimization and perpetration: a prospective investigation. Child Abuse Negl 2014;38(4):650663.

31. McKinney CM, Caetano R, Ramisetty-Mikler S, Nelson S. Childhood family violence and perpetration and victimization of intimate partner violence: findings from a national population-based study of couples. Ann Epidemiol 2009;19(1):25-32.

32. Wolfe DA, Wekerle C, Scott K, Straatman AL, Grasley C, ReitzelJaffe D. Dating violence prevention with at-risk youth: a controlled outcome evaluation. J Consult Clin Psychol 2003;71(2): 279-291.

33. Capaldi DM, Knoble NB, Shortt JW, Kim HK. A systematic re- view of risk factors for intimate partner violence. Partner Abuse 2012;3(2):231-280.

34. Kim HK, Laurent HK, Capaldi DM, Feingold A. Men's aggression toward women: a 10-year panel study. J Marriage Fam 2008; 70(5):1169-1187.

35. Ahmadabadi Z, Najman JM, Williams GM, Clavarino AM. Income, gender, and forms of intimate partner violence. J Interpers Violence 2017:886260517719541.

36. Palmetto N, Davidson LL, Breitbart V, Rickert VI. Predictors of physical intimate partner violence in the lives of young women: victimization, perpetration, and bidirectional violence. Violence Vict 2013;28(1):103-121.

37. Pepler D. The development of dating violence: what doesn't develop, what does develop, how does it develop, and what can we do about it? Prev Sci 2012;13(4):402-409.

38. Langhinrichsen-Rohling J, Capaldi DM. Clearly we've only just begun: developing effective prevention programs for intimate partner violence. Prev Sci 2012;13(4):410-414.

39. Wray AM, Hoyt T, Gerstle M. Preliminary examination of a mutual intimate partner violence intervention among treatmentmandated couples. J Fam Psychol 2013;27(4):664-670. 